\title{
The University for Industry Pilot Project
}

M. Thorne

Vice Principal and UfI Pilot Project Director

Napier University

Edinburgh

UK

e-mail:mp.thorne@napier.ac.uk

\section{H. Milner}

Project Manager for the University for Industry

and Assistant Director of Learning Development Services

University of Sunderland

Sunderland

SR1 3SD

$U K$

e-mail:helen@ufi.org.uk or helen.milner@sunderland.ac.uk

\begin{abstract}
The new UK Government of $1^{\text {st }}$ May 1997 stressed their commitment to a skills revolution featuring a University for Industry (Ufl) aimed at increasing the competitiveness and the employability of the UK workforce. A pilot project was established in early 1997, in the North East of England, to prototype the Ufl and test some of the techniques which a national implementation might use. Its model is one of private-public partnership, where the Ufl is not a new provider but a broker of new and existing courses and a catalyst to create a culture, which will embrace lifelong learning.
\end{abstract}

Keywords

Education policy, Lifelong learning, Private-public partnership 


\section{INTRODUCTION}

The UK needs a skills revolution, if it is not to slip down the international league table of competitiveness. This revolution requires step-changes in people's demand for learning and in their ease of access to education and training opportunities. The new UK Government of $1^{\text {st }}$ May 1997 stressed their commitment to education and training; one element of their new education policy is proposed to be a University for Industry. The UfI will increase the competitiveness and the employability of the UK workforce.

In the UK, each time there is an educational transition - people moving from school to college, or from college to university - individuals are lost from the educational system and they never return to learning. This is relevant at all levels from basic skills, through university and into post-graduate study. At the basic levels, literacy is a problem for those both in and out of work, at the highest level doctors and engineers need to update their skills every 8 to 10 years. In some professions the need for lifelong learning commitment is recognised, in most it is not.

In December 1996 the Institute of Public Policy Research (IPPR) published a report The University for Industry: creating a National Learning Network. It was the culmination of over two years research by IPPR's Josh Hillman which had included work with key figures, in particular working with the University of Sunderland. The research was based on approaches made by prominent members of the (at that time) Labour Party in opposition, Gordon Brown and David Blunkett (now Chancellor of the Exchequer and Minister of State for Education respectively), and was supported by them.

The University for Industry (UfI) model as set out in the report (Hillman, 1996) describes a new type of organisation which would not be another provider, but would rather be a broker, connecting individuals and companies to learning programmes that best met their needs.

The University for Industry will move learning out of the institutions and nearer to where people are, culturally as well as geographically. By bringing together oganisations which already exist into a network it will enable education to be sold to millions of people across the UK rather than in small isolated pockets. The University of Sunderland has been working on this agenda for the past seven years.

The IPPR model has the following key elements:

- The UfI as one gateway to education and training: an impartial broker.

- The Ufl must increase the demand for learning.

- The UfI must increase participation. 
- It needs to be user led, not provider led.

- It will stimulate lifelong learning.

-It will commișsion courses or materials.

A pilot project was established in early 1997 to prototype the UfI and test some of the techniques which a national implementation might use. The project is led jointly by IPPR and the University of Sunderland and is based in the North East of England. There is a strong, strategic collaboration between regional and national partners, including companies, TECs, local authorities, colleges, universities and voluntary agencies. Funding is based on major sponsorship from Sunderland City Training and Enterprise Council, Sunderland City Council and the NatWest Bank Group, but highlights a public private partnership with many other companies and organisations providing substantial benefits "in kind" including the National Extension College and the BBC. The evaluation of the pilot is funded by the Department for Education and Employment (DfEE).

\section{THE UFI IS A BROKER}

The UfI is drawing on existing provision into a framework based on a computer network; using this people can choose between difference course being offered by different providers. All of the courses are delivered by provider organisations and the role of the UfI is to broker these opportunities and not to deliver them.

The pilot has established a one-stop-shop for education and training. There is a freephone line which is available 14 hours a day, 7 days a week providing easy and efficient access to information and advice as well as to telephone booking for a range of tasters and courses. Over 800 calls were made to 0800262639 during October (1997) indicating an instant response to this mode of information provision.

At the heart of the University for Industry pilot is innovative use of the Internet. Wherever someone is in the region they can use the Internet to browse information, course details, opening hours of learning centres, make a request for a full pack or book onto a free taster or a course. In the home, the workplace, and at all of the learning centres people have access to the online UfI system.

The system includes an online database of courses which can be searched by staff in the call centre as well as by anyone on the Internet. It includes online booking for courses and online learning for those who want it.

The Internet is the medium-tech approach for the UfI pilot project. A sophisticated online system has been designed for the pilot by two small companies: The Leighton Group, in Sunderland, and Telematica in Swindon. 
The pilot is embracing the benefits of here-and-now technology. There have been no new cables put into the ground. Some centres have high-speed links to the Internet others have modem links with standard telephone lines. If UfI is to be egalitarian, it must rely on a range of access points with a range of types of interaction. The pilot has chosen the Internet as the common channel as it is the only cost effective solution to carry the service. It is also scaleable to include more learners and more partners with an affordable level of investment at a future date if required.

One of the most innovative aspects of the project is that the providers are able to add, modify and delete course details directly onto the database over the Internet from work or from home. This allows them to take responsibility and control for their own course listings rather than having to channel all information through a central administration.

\section{LEARNING CENTRES}

The University for Industry is based around a network of learning centres (in November 1998 there were 34$)$. These centres are closely matched to people's lifestyles. Of course there are centres in the University, colleges and schools, they are also in resource or training centres in companies and big organisations, and in leisure locations such as the Sunderland Football Club stadium and Learning World, a joint University of Sunderland and Gateshead College learning centre at the MetroCentre shopping complex (the biggest indoor shopping centre in Europe). There are learning centres in the communities in which people live, recognising learners' loyalty to their local environment.

The minimum requirements for a UfI pilot learning centre are one computer linked via the Internet to the University for Industry project computer system - the virtual engine for the Ufl - a named contact person and advertised open access times. Some centres have one computer, others have over 250 .

\section{THE UNIVERSITY OF INDUSTRY IS NOT A PROVIDER}

The University for Industry pilot has established a brokerage between the potential learners and the providers who can support their learning.

The brokerage provides information about courses. All of the contents of the courses on offer via the UfI pilot project are the responsibility of the providers involved. These providers are the University of Sunderland, the colleges of Gateshead, Newcastle and the City of Sunderland and some school and community provision, as well as commercial providers such as distance learning offered by the National Extension College. 
The pilot is focused on what might be called "skills for work". Courses fit into areas such as IT and the Internet, communication, using number and finance, the business environment and skills for small businesses.

Free tasters are being used as one of the elements in the marketing armoury. They can allow those nervous, disinterested in or out of the habit of formal learning to develop, or regain, confidence in their ability to learn. There are five tasters currently on offer - IT for the Terrified, Internet for All, Time Management, Writing Successful Job Applications and Communicating in the Electronic Office. These are all offered free of charge and are available at all 34 learning centres content is based within workbooks which are sent to the learners at home and can be used in the centres; tutor support is available face-to-face at the centres or via telephone. These are not courses, they are not assessed or examined (all concepts which are barriers to participation) but they are a first step towards a course - and progression is a key factor to the pilot project.

As Learning Works (Kennedy, 1997) addresses: "The inequality of the current arrangements is the most compelling reason for change. Those who have already succeeded are now most likely to take part in further learning."

One of the pilot UfI success stories is a young man, 17 years old, who left school with no qualifications and was unemployed; he was outside an education system which had failed him. He was attracted to the Internet for All taster and then progressed onto another taster, Communicating in the Electronic Office, these were free and interesting. He spent time in the learning centre in the local library with support from a tutor, but has spent more time on his own with the workbooks using the computer in independent study. He has now registered on a course and is working; he has developed confidence as well as essential employability skills.

A fundamental idea behind the pilot is to allow learners to start learning as soon as possible rather than wait until the start of the next academic term. A face-to-face course will start just as soon as the minimum number required for a cohort have been registered.

For those who wish to start immediately or are forced by circumstance to study on their own the pilot offers a number of distance learning courses. These are from many providers including the National Extension College (largely paper based) and Cambridge Training and Development (multimedia and online learning).

The pilot UfI project is removing barriers to learning - there is one simple access point for all information, there is a range of subjects, at a range of levels and using a range of delivery mechanisms. The Ufl as broker begins with the marketing and ends when the learner is booked onto a full course with a provider; it is at that moment that the provider takes over as contact point. 


\section{EFFECTIVE MARKETING}

Money must be spent to tackle under-participation. As Learning Works (Kennedy, 1997) says: "A society which is so expert in selling goods should be able to find ways of selling education."

Education must compete with business in selling. The marketing of learning must be very professional and needs to consider the marketing messages as well as the media used.

Tele-access, via the pilot project's free phone telephone number, offers truly innovative ways of selling educational opportunities, monitoring learners and providing information about the next appropriate step. Follow-up calls to all those who have previously enquired maintains contact and enables further direct selling.

The backbone of the pilot project is telemarketing, leaflets through household doors, a poster campaign on buses and at a range of lifestyle locations, as well as events which includes family learning. We are working with partners in newspapers, radio and television to raise the local profile of the unique access to learning opportunities the pilot is bringing to the region.

A range of messages are being tested - all aimed at making people currently nct engaged in learning to pick up the telephone and ring. Messages such as "Earn More, Learn More" and "No More Excuses" highlight the benefits that learning will bring as well as find answers for all the reasons people give for not wanting or not needing courses. These are aimed both at employed and unemployed people.

The initial marketing effort is directed at achieving one single key response - dial 0800262639 for more information. The telematic management tools gather details for market research as well as market intelligence, indicating marketing successes and information regarding important gaps in provision.

The UK needs to affect a change in attitude to learning. Society needs to value learning and to appreciate the necessity of the lifelong nature of it. The BBC are working closely with the pilot to discover ways in which a national broadcaster can support this shift in social beliefs. Senior managers in companies are also involved in demonstrating the value, which they place on training.

\section{COMPANIES}

Improving competitiveness and performance of individuals and of companies is important for Ufl. The project involves a number of companies in the region. The strategy includes working alongside current training plans and in-house provision 
to ensure that employees have access to the opportunities that the pilot offers as well as integration with existing development.

Lite-On, an electronics firm in Ashington Northumberland, has opened up their training room to all employees, employees friends and family, and parents and staff of a local school. All the Ufl tasters are on offer there as well as access to the online system to book onto further courses that might interest them.

Vaux, a Sunderland-based brewery, and Sainsbury's, a supermarket, both see that there is a dual benefit in providing opportunities to the general public at the same time as involving their staff.

Roadshows in the canteen at lunchtime is one way in which the pilot is directly interacting with employees - discussing the ways in which the pilot can interest them as well as listening to ways in which the pilot does not meet their needs.

The nature of a provider is changing during the project. Companies such as Siemens, and Black and Decker, are offering places on their own training courses to other companies and to the long-term unemployed. This helps to increase both the competitiveness of the supply-chain (Siemens) and the skills of their future workforce (Black and Decker). The role of UfI is to broker the courses to the individuals interested in taking part. Unions too are running courses and supporting learning centres within factories.

\section{SUMMARY}

The pilot will be completed in July 1998. It is attempting to allow potential learners to be active not passive, making active choices about their learning from realistic and relevant information which the pilot UfI manages.

The DfEE will be formally evaluating the pilot project enabling all of the key elements and issues to be discussed and analysed. Other important issues such as funding and quality have been debated locally and a working model put into practice. The Further Education Funding Council is working closely with the pilot and is keen to explore ways in which the current funding methodology does and does not match the learning support in the project.

The project puts learning right at the centre of people's lives - using commercial marketing techniques to sell learning and to link individuals into new and existing educational opportunities. The one-stop-shop approach provides flexible access to hundreds of courses. People can learn when and where it suits them. In the first four months of operation over 1000 registrations have been made using the UfI project brokerage. The University for Industry will continue to evolve until it is embedded as an essential plank in the lifelong learning culture of the UK. 


\section{REFERENCES}

Hillman J, The University for Industry: creating a National Learning Network IPPR 1996 ISBN 1860300510

Kennedy H, Learning Works - widening participation in further education Widening Participation Committee Report, FEFC 1997, p. 50

Kennedy $\mathrm{H}$, Learning Works - widening participation in further education Widening Participation Committee Report, FEFC 1997, p. 102

\section{BIOGRAPHIES}

Michael Thorne is currently Vice Principal at Napier University in Edinburgh. Until December 1997 he was the Pro Vice-Chancellor at the University of Sunderland where his responsibilities were for Learning and Student support, recruitment, the Student Charter, and IT strategy. He is the author or co-author of 11 books and a large number of academic papers and articles.

Helen Milner is Assistant Director of Learning Development Services and Project Manager of the University for Industry Pilot Project. Helen has worked at the University of Sunderland since 1992. She has worked for over eleven years in online and interactive communications networks within education including for The Times and in Australia. Her University role includes managing EU funded projects, developing flexible learning materials and developing and implementing learning strategies for teaching and learning. 